\title{
Linking climate variability, productivity and stress to demography in a long-lived seabird
}

\author{
William H. Satterthwaite ${ }^{1,2, *}$, Alexander S. Kitaysky ${ }^{3}$, Marc Mangel $^{2,4}$ \\ ${ }^{1}$ Marine Resources Assessment Group (MRAG) Americas, Capitola, California 95010, USA \\ ${ }^{2}$ Center for Stock Assessment Research, Department of Applied Mathematics and Statistics, University of California \\ Santa Cruz, Santa Cruz, California 95064, USA (present address for W.H.S.) \\ ${ }^{3}$ Institute of Arctic Biology, Department of Biology and Wildlife, University of Alaska Fairbanks, Fairbanks, Alaska 99775, USA \\ ${ }^{4}$ Department of Biology, University of Bergen, Bergen 5020, Norway
}

\begin{abstract}
We examined the reproductive ecology of black-legged kittiwakes Rissa tridactyla in several breeding colonies in the North Pacific to test if inter-annual changes in the Pacific Decadal Oscillation (PDO), Winter Ice Cover (ICI), or local sea-surface temperature (SST) predict changes in productivity (fledglings per nest) or nutritional stress (corticosterone). We explored the implications of the observed variation in productivity and stress for projected population dynamics based on a previously demonstrated corticosterone-survival relationship. Although productivity was highly variable ( 0 to 0.9 fledglings nest ${ }^{-1}$ ), the relationships between productivity and environmental indices were weak, with local SST providing slightly more explanatory power than PDO or ICI, suggesting that local factors rather than large-scale climate variability may determine variation in productivity. The relationships between stress and environmental indices were stronger than the relationship between productivity and environment. The measured response of stress to environment showed opposite signs between the southern and northern colonies, and typically implied annual mortality rates varying from 11 to $17 \%$. The observed relationships between climate and stress indicate that anticipated warming might bring at least short-term demographic benefits for kittiwakes in the Bering shelf region, while having negative impacts on birds breeding in the Gulf of Alaska and western Aleutians. We predict decline (without immigration) for colonies with the lowest productivity and conclude that climate variability is likely to affect survival of North Pacific kittiwakes on a region-specific basis. Longevity of these birds may not always be sufficient to buffer their populations from low reproductive performance.
\end{abstract}

KEY WORDS: Demographic consequence - Corticosterone • Kittiwake . Survival . Food availability $\cdot$ Colony

Resale or republication not permitted without written consent of the publisher

\section{INTRODUCTION}

Predicting the effects of changing climate on populations of marine top predators is a major challenge in ecology. Despite substantial work linking seabird demography to climate variability (Jenouvrier et al. 2005, Frederiksen et al. 2007, Sandvik \& Erikstad 2008, Wolf et al. 2009, Oro et al. 2010, Barbraud et al. 2011), we are still very limited in our ability to make generalizations. Seabird responses vary on a location-specific basis (i.e. Gaston et al. 2005, Irons et al.
2008, Shultz et al. 2009), which may reflect different tradeoffs between survival and reproduction being favored in different locations (Coulson 2002). However, characterizing the regional variability of demographic responses to changing environments is difficult because of the intensive, long-term study typically needed to characterize demography and, in particular, adult survival.

The most comprehensive and conclusive studies of seabird demography at the colony level must involve long-term collection of information on both fecundity 
and survival of individuals. However, such study is logistically feasible at only a small number of colonies. In addition, the representativeness of small-scale studies for assessing the regional effects of climate on a seabird population is unclear. Long-term information on survival is lacking for many regions of great economic or ecological importance, and limited resources make it unlikely that intensive, long-term studies will be initiated. The dual requirements for intensive, long-term study (generally requiring focusing on 1 or a few sites) to estimate demographic rates and for integrating information on the localized responses of multiple colonies spread out over space thus present a major challenge to overcome (Brown et al. 2011), and an alternate approach that does not require such intensive demographic study may be needed to develop an understanding at the regional scale.

Physiological measurements, and in particular stress hormones with known correlations with food supply and survival (e.g. Romero \& Wikelski 2001, Brown et al. 2005, Blas et al. 2007, Kitaysky et al. 2010, Satterthwaite et al. 2010), provide a practical alternative for assessing likely population dynamics in datalimited systems. Using black-legged kittiwakes Rissa tridactyla in the North Pacific as a model system, we examined the relationship between climate variability and demographic performance by leveraging recent advances in measuring seabird nutritional stress (as reflected in secretion of corticosterone, hereafter CORT) and its relation to demographic rates (Kitaysky et al. 2010, Satterthwaite et al. 2010).

Major climate changes have been observed in the northern Pacific over the last few decades (Springer 1998, Anderson \& Piatt 1999, Hunt et al. 2002, 2008). Coincident with these changes, piscivorous seabirds declined in the continental shelf areas of the central and southeastern Bering Sea (Springer 1998, Hunt \& Byrd 1999, Hunt et al. 2002, Byrd et al. 2008a). On the other hand, several colonies in the Aleutian Archipelago increased in size (e.g. Renner \& Williams 2005), suggesting that climate variability might have differential effects on birds breeding in different regions of the North Pacific. This set of colonies allows the examination of relationships between environmental changes and population processes (reproduction and survival) to understand how seabird populations respond to climate change. Survival has not been directly measured in most of these colonies (except Cook Inlet in the late 1990s; Piatt 2004), but long-term measures of nutritional stress are available (Kitaysky et al. 2010, their appendix), and a link between corticosterone and mortality has been established (Kitaysky et al. 2010, Satterthwaite et al. 2010).
In the present paper, we tested the hypothesis that major climatic indices and local measures of seasurface temperature (SST) can predict productivity and CORT levels (and thus inferred food stress and adult mortality risk) for multiple black-legged kittiwake colonies in the Gulf of Alaska (GOA), Aleutian Archipelago, and southeastern Bering Sea regions. Seabird reproductive performance, survival, and CORT levels have previously been linked to local variation in food availability and SST (Kitaysky et al. 2007, 2010, Shultz et al. 2009), but our study addressed these links on a larger geographic scale (i.e. Aleutians and Bering Sea) and incorporated large-scale climatic indices in addition to local variation in SST. In the northern Pacific, broad-scale indices of climate such as the Pacific Decadal Oscillation (Mantua et al. 1997) and the extent of winter ice cover in the Bering Sea (Overland \& Stabeno 2004) encompass ocean-atmospheric patterns of short-term (interannual) and long-term (decadal) climate variability. These indices provide a measure of whether years are relatively warm or cold, and are strong predictors of ecological processes (Hare \& Mantua 2000, Hunt et al. 2002, Mueter \& Litzow 2008). Knape \& de Valpine (2011) suggested that local rather than regional climate measures could provide better predictions, and Shultz et al. (2009) linked highly localized measures of SST to lay dates and resultant reproductive success in Cook Inlet; thus, we explored the predictive power of local SST as well.

To explore the potential for location-dependence of climate effects, we investigated whether linkages between environmental indices and bird performance are similar across regions. Location-specific responses to climate (e.g. Gaston et al. 2005, Frederiksen et al. 2007) have the potential to complicate predicting effects of climate change (Brown et al. 2011), so we explored relationships between the environment and demographic performance for multiple colonies separated by as much as $2000 \mathrm{~km}$.

We also assessed the relative impacts of predicted changes in productivity and stress in the different colonies by building demographic models based on measured productivity and inferred (from CORT) survival in the different colonies to project colony performance in the future. As with other demographic models, we emphasized relative over absolute predictions (Beissinger \& Westphal 1998, Brook et al. 2000). Unifying productivity and survival measurements into a single demographic model provides important insight into the importance of observed variation in fecundity and stress for population performance. Although the sensitivity of the population growth rate to adult sur- 
vival is well appreciated for long-lived species (Morris et al. 2008), it is known that the demographic parameters with the highest sensitivities are often the least variable (Pfister 1998). In long-lived seabirds, 'prudent parent' behavior (Cam et al. 1998) may result in little observed variation in adult survival. Since the impacts of changing vital rates on demography depend on their sensitivity and magnitude of variation (Wisdom et al. 2000), the realized importance of variation in productivity may be higher than expected.

Thus, our study provides a unified framework for assessing the impacts of local and regional environmental variability on both predicted survival and reproduction in multiple seabird colonies. By analyzing multiple colonies, we could assess the generality of relationships identified in specific locations. By incorporating estimates of reproduction and survival into a unified demographic model, we were able to assess the likely effects of observed variation on colony performance and long-term viability. This allows inferences to be made about the projected performance of each colony, and the likely response of colonies in each region to projected climate change.

\section{MATERIALS AND METHODS}

\section{Study system}

Black-legged kittiwakes Rissa tridactyla are longlived (Hatch et al. 1993, Golet et al. 1998, Piatt 2004) and generally lay 2 eggs clutch $^{-1}$. Data were collected on population sizes, productivity, and stress hormone levels for black-legged kittiwakes breeding in 6 colonies in the North Pacific region (Fig. 1). Duck Island and Gull Island are located in Cook Inlet in the GOA, $100 \mathrm{~km}$ apart, with Duck Island surrounded by warm estuarine waters, and Gull Island by cooler oceanic water (Piatt et al. 2002, Kitaysky et al. 2010). Saint Paul and Saint George (Pribilof Islands) are located in the Bering Sea; the distance between the islands is $\sim 60 \mathrm{~km}$, with St. George near $(25 \mathrm{~km})$ the edge of the Bering Sea shelf (Byrd et al. 2008a). Bogoslof Island is in the central Aleutians, and Buldir Island is in the western Aleutians; both are surrounded by deep ocean water (Shultz \& Kitaysky 2008).

\section{Environmental metrics}

We used environmental metrics describing SST and the extent of winter sea ice cover to predict variation

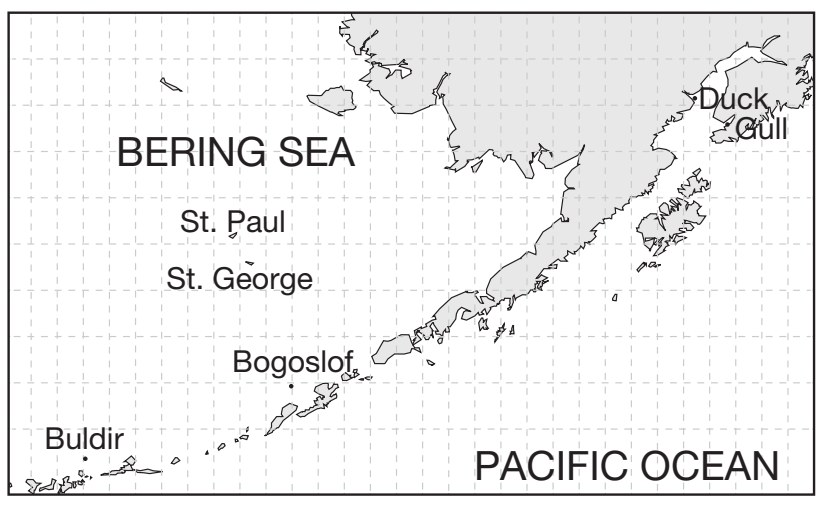

Fig. 1. Study region. This map was generated using a rectangular projection, grid lines equal $1^{\circ}$ of latitude or longitude. Each degree of latitude corresponds to $\sim 111 \mathrm{~km}$, while each degree of longitude corresponds to $\sim 71 \mathrm{~km}$ at the southern border of the map or $52 \mathrm{~km}$ at the northern border

in seabird productivity and stress. Data were obtained from the National Oceanic and Atmospheric Administration (NOAA; detailed descriptions of the parameters can be found at www.beringclimate.noaa.gov/). For a basin-scale summary of SSTs, we obtained summer Pacific Decadal Oscillation values (PDOs, which integrate SSTs in the North Pacific in June, July and August; Mantua et al. 1997) from www.beringclimate.noaa.gov/. We obtained Ice Cover Index values (ICI, which represent the ice concentration from January 1 to May 31 over the area between $56^{\circ} \mathrm{N}, 163^{\circ} \mathrm{W}$ and $58^{\circ} \mathrm{N}, 165^{\circ} \mathrm{W}$; Overland \& Stabeno 2004) from the National Snow and Ice Data Center (NSIDC), available at www.beringclimate.noaa.gov/. We obtained estimates of SST from the Extended Reconstructed Sea-Surface Temperature dataset (ERSST 3b; Smith et al. 2008) at www.ncdc.noaa.gov/ersst/, using ERSST for the $2^{\circ}$ block including each colony, with data available through December 2008. Measuring temperature over $2^{\circ}$ of latitude and longitude results in an area of approximately $200 \mathrm{~km}$ on each side, which is similar to the foraging range of kittiwakes (e.g. $59 \mathrm{~km}$ range and $165 \mathrm{~km}$ trip length reported by Kotzerka et al. [2010], foraging trips from the Pribilofs may be even longer, Paredes et al. [unpubl. data]). We averaged together March to May SSTs for a spring estimate representative of pre-laying conditions and from June to August for a summer estimate representative of the rearing season. We selected each of these indices on the basis of an a priori mechanistic hypothesis (e.g. Hunt et al. 2002, 2011). For example, SST during the breeding season provides a measure of current environmental conditions (e.g. stratification of the water column during the summer, which might affect vertical fish distribution), on either a local (SST) or regional 
(PDOs) scale. The extent of winter sea ice cover is related to the formation of a cold pool and associated effects on biogeography and the transition between arctic and subarctic community characteristics (Mueter \& Litzow 2008). The Oscillating Control Hypothesis (Hunt et al. 2002, 2011) proposes that the timing of phytoplankton production is affected by the timing of ice retreat, and the timing of bloom affects phytoplankton availability to zooplankton and thus food availability for fish and competition between seabirds and other piscivores.

\section{Productivity and count data}

We estimated productivity and relative population size based on counts made in reference plots reported in United States Fish and Wildlife Service (USFWS) refuge reports and other data sources (McClintock et al. 2010 for Saint Paul; Shannon et al. 2010 for Saint George [productivity data were collected as described in Kitaysky et al. 2010 for Duck and Gull Island, with counts for both islands and productivity for Gull Island from Piatt et al. 2002]; Renner \& Williams 2005 for Bogoslof [with an update for 2008 productivity from J. Williams pers. comm.]; Freeman et al. 2010 for Buldir). We standardized these reference counts (but not productivity values) relative to the maximum reference count observed for each colony. For all colonies except Bogoslof, the productivity index used was chicks fledged per nest. For Bogoslof, the productivity index was calculated from the number of chicks per nest late in the rearing season, but before actual fledging. This may slightly overestimate how many chicks actually fledged. For the Pribilof islands, we excluded data from before 1984 due to changes in sampling methods, a break in the data, and a lack of ICI data for the earliest years.

\section{Measures of stress}

We collected measurements of baseline CORT from a variable number of birds in each colony each year (Table S1 in Supplement 1 at www.int-res.com/ articles/suppl/m454p221_supp.pdf; not every colony was sampled every year). Collection and measurement of CORT in all colonies followed the same procedures as previously reported by Kitaysky et al. (2010). We used baseline CORT since it reflects current food availability (Kitaysky et al. 2010) and is a predictor of apparent survival of kittiwakes (Satterthwaite et al. 2010).

\section{Statistical analyses}

We examined the relationship between each environmental index and mean productivity and mean CORT at each location for each year. We used information theoretic techniques to distinguish whether it was better supported statistically to estimate parameters for all colonies independently or to estimate shared parameters for colonies within one or more regions (see 'Colony-scale versus regional responses'). When analyzing time series data, temporal autocorrelation leads to non-independence of samples (Pyper \& Peterman 1998, Brown et al. 2011). Thus, we performed generalized least squares models (GLS; Pinheiro \& Bates 2000) assuming autoregressive order 1 errors within each location, implemented via the 'nlme' package in R (R Development Core Team 2009, Pinheiro et al. 2010). We modeled each performance metric (productivity and CORT) as a function of location, environmental metric, and their interaction. We used Akaike's information criterion (AIC; Burnham \& Anderson 2002) to compare model formulations where location was the set of individual colonies or to compare various combinations where colonies within regions were combined. To summarize patterns of common or divergent responses, we also calculated correlations among islands in productivity and CORT, using the techniques of Pyper \& Peterman (1998) to account for autocorrelation when assessing significance.

We transformed all environmental metrics to $z$ scores (so they had a mean of 0 and a SD of 1 ) to directly compare the sensitivity of performance metrics (productivity, stress) to the observed range of variation in each environmental measure. To obtain normally distributed error values, we performed the empirical logit transform (Warton \& Hui 2011) on productivity and log-transformed CORT. Because the performance metrics are measured on different scales with different transformations, their sensitivities cannot be directly compared.

We explored the extent to which CORT can predict productivity by running a GLS model with logit productivity as the response variable and location, log CORT, and their interaction as independent variables, defining locations as in the best model for productivity as identified above.

\section{Estimating adult survival from stress data}

We estimated overall survival for colonies or years as the means of the survival predicted for each indi- 
vidual sampled in that colony or year using the model of Satterthwaite et al. (2010). This is an empirically derived relationship between CORT and mortality based on long-term resighting data of birds first marked and sampled for CORT in 1996 to 1999 on Duck and Gull Islands in Cook Inlet, GOA. Specifically, the estimated probability of mortality over the next year for a bird with a baseline CORT measurement of $x\left(\mathrm{ng} \mathrm{ml}^{-1}\right)$ is:

$$
m(x)=\frac{\mathrm{e}^{-2.399+0.0803 x}}{1+\mathrm{e}^{-2.399+0.0803 x}}
$$

\section{Demographic model}

We generated estimates of expected lifetime reproductive success for each colony under mean conditions as follows. We estimated reproductive lifespan as the inverse of adult mortality rate (Bókony et al. 2009), yielding the expected number of reproductive events in an individual's lifetime. We estimated annual mortality based on the expected value corresponding to the mean of annual mean CORT measures in each colony. Since our estimates of survival varied across years, we explored the range of lifespans implied by the lowest and highest annual survival estimates. To calculate expected lifetime reproductive output (chicks fledged), we multiplied this expected number of reproductive events by mean productivity. To yield an estimate of the population growth rate, we multiplied expected lifetime reproductive output by 0.5 times the expected survival from a fledged chick to first reproduction (to account for only females laying eggs), inferred from the literature as 0.57 (Suryan et al. 2000). If the resulting value $\left(R_{0}\right)$ is $<1$, we predict populations will decline if conditions remain similar through time, $R_{0}=1$ implies stability and $R_{0}>1$ implies population growth. This is equivalent to a lifetable analysis defining $l_{X}$ (survival from newborn [fledging] to age $x$ and $m_{x}$ (fecundity at age $x$, in terms of newborn females where newborn is defined as a fledged chick) estimating $R_{0}$ as $\Sigma l_{X} m_{X}$.

\section{Uncertainty in demographic projections}

There are 4 major sources of uncertainty in our demographic projections. (1) The first source of uncertainty is whether the relationship between CORT and survival in the multiple colonies in the present study is the same as in the Cook Inlet colonies used to parameterize the survival probability in Satterth- waite et al. (2010) or whether survival from fledging to first reproduction is the same as that Suryan et al. (2000) reported for a colony in Prince William Sound, GOA, eastern North Pacific. In the absence of longterm mark-recapture studies in all of the colonies under consideration, we cannot directly quantify our uncertainty for how consistent the CORT-survival relationship is across colonies. However, Satterthwaite et al. (2010) present support for a consistent relative, if not absolute, effect of CORT on survival at multiple locations. This was based on the 2 Cook Inlet colonies, which are separated by $\sim 100 \mathrm{~km}$. We might expect more variation in the relationship at larger scales; however, the surrounding oceanography is quite different for Duck Island (warm estuarine waters) and Gull Island (colder oceanic waters), and they differ substantially in productivity (Kitaysky et al. 2010), so the CORT-survival relationship appears robust to differences in geography and biology.

(2) The effect of annual variability, which typically decreases realized long-term demographic performance relative to that expected from the mean value (Morris \& Doak 2002). Adequately characterizing the effects of yearly variability on demographic performance requires many years of data on the full life cycle (Morris \& Doak 2002); however, unless the strength of stochastic effects vary substantially among colonies, this should not greatly affect comparisons of relative performance.

(3) The bias in estimates of survival. We might overestimate mortality due to negative effects of blood draw to measure CORT (Brown \& Brown 2009). We have only limited data to directly assess the effects of blood draw; however, in 1998, 114 birds had blood drawn, 15 of which were never resighted, while 42 birds were banded but had no blood drawn, 3 of which were never resighted (J. F. Piatt et al. unpubl. data for the Cook Inlet colonies). While a higher fraction of birds with blood drawn were never resighted, this difference is not statistically significant $\left(\chi^{2}=1.09, \mathrm{p}=0.30\right)$. Thus, we cannot rule out a small deleterious effect of blood draw, but do not see strong evidence for it. We drew a maximum of $1 \mathrm{ml}$ of blood (often less), or $0.25 \%$ by mass for a typical $400 \mathrm{~g}$ kittiwake. This is unlikely to have major effects on survival (Sheldon et al. 2008). In addition, Satterthwaite et al. (2010) assumed that most failures to detect a bird that was still alive reflected skipped reproduction rather than failing to detect a bird present in the colony. Mortality was therefore estimated as the probability of dying before returning to the colony rather than on a strictly annual basis, which may overestimate 
the annual mortality rate (see Satterthwaite et al. 2010 for fuller discussion of this issue and the rationale behind the approach chosen).

(4) Limited sample size creates uncertainty about mean productivity, mean CORT, and the parameterization of the CORT-survival relationship. In Supplement 2 at www.int-res.com/articles/suppl/ m454p221_supp.pdf, we present a calculation of Bayesian credible intervals on our estimates of $R_{0}$ that incorporates uncertainty due to sample size. However, as we cannot directly quantify our other sources of uncertainty, we emphasize that the estimated $R_{0}$ values are more useful for making comparisons among colonies than predictions of absolute performance. These credible intervals were calculated via Markov Chain Monte Carlo sampling implemented using the MCMCpack library (Martin et al. 2011) of R (R Development Core Team 2009).

\section{RESULTS}

\section{Colony-scale versus regional responses}

The relationship between CORT and any environmental metric was best described at the regional scale for Cook Inlet and Pribilof colonies of Rissa tridactyla, while it was best described for the Buldir and
Bogoslof colonies independently (Table 1a). CORT was strongly, significantly, and positively correlated between the 2 Pribilof colonies and the 2 Cook Inlet colonies. Correlations between more distant colonies were generally weak or negative (Table 2). Productivity was best described at the individual-colony level for Bogoslof, Buldir, Duck, and Gull Islands separately, but together for both Pribilof colonies (Table 1b). Productivities on the Pribilofs (St. Paul and St. George) were highly and significantly correlated (Table 3). Productivities among other colonies showed some signs of synchrony, but no other correlations were significant after accounting for autocorrelation.

\section{Productivity}

Using the best-supported location set of Bogoslof, Buldir, Duck, Gull, and Pribilofs, a GLS model of logit productivity as a function of PDOs (z-score), location, and their interaction revealed a significant effect of location ( $p<0.001)$, but, despite the high variation in productivity (0 to 0.9 ; Fig. 2 ), there was no significant effect of PDOs or its interaction with location ( $p>0.86)$. Results were similarly nonsignificant for ICI $(p>0.18)$ and summer SST $(p>$ 0.10 ) and marginally significant for spring $\operatorname{SST}(\mathrm{p}=$

Table 1. Rissa tridactyla. $\Delta$ AIC (Akaike's information criterion) scores for different resolutions of location effects (colony versus regional groupings) for generalized least squares (GLS) models of performance metrics: (a) log CORT (corticosterone) and (b) logit productivity) as functions of location, environmental index, and their interactions. The best model for a particular response variable has $\Delta \mathrm{AIC}=0$, models with $\Delta \mathrm{AIC}<2$ receive comparable support, and models with $\Delta \mathrm{AIC}>4$ receive considerably less support. PDO: Pacific Decadal Oscillation; ICI: ice cover index; SST: sea-surface temperature

\begin{tabular}{|c|c|c|c|c|}
\hline Location groupings & PDOs & $\mathrm{ICI}$ & SST spring & SST summer \\
\hline \multicolumn{5}{|l|}{ (a) Log CORT response to environmental metrics } \\
\hline All colonies independently & 15.50 & 11.21 & 6.91 & 6.64 \\
\hline Pribilofs + remaining colonies & 7.50 & 5.23 & 3.31 & 4.16 \\
\hline Cook Inlet + remaining colonies & 7.94 & 6.64 & 4.12 & 3.23 \\
\hline Aleutians + remaining colonies & 16.61 & 15.58 & 12.06 & 13.53 \\
\hline Cook Inlet + Pribilofs + remaining colonies & 0.00 & 0.00 & 0.00 & 0.00 \\
\hline Cook Inlet + Aleutians + remaining colonies & 9.14 & 10.77 & 9.16 & 9.96 \\
\hline Pribilofs + Aleutians + remaining colonies & 8.62 & 9.47 & 8.50 & 10.90 \\
\hline Pribilofs + Cook Inlet + Aleutians & 1.20 & 4.14 & 5.17 & 6.86 \\
\hline \multicolumn{5}{|c|}{ (b) Logit productivity response to environmental metrics } \\
\hline All colonies independently & 3.52 & 3.15 & 1.33 & 3.52 \\
\hline Pribilofs + remaining colonies & 0.00 & 0.00 & 0.00 & 0.00 \\
\hline Cook Inlet + remaining colonies & 20.97 & 23.37 & 21.59 & 20.97 \\
\hline Aleutians + remaining colonies & 23.20 & 26.06 & 22.60 & 23.20 \\
\hline Cook Inlet + Pribilofs + remaining colonies & 18.22 & 21.05 & 20.86 & 18.22 \\
\hline Cook Inlet + Aleutians + remaining colonies & 31.55 & 34.73 & 33.51 & 31.55 \\
\hline Pribilofs + Aleutians + remaining colonies & 20.70 & 24.06 & 21.95 & 20.70 \\
\hline Pribilofs + Cook Inlet + Aleutians & 29.49 & 33.26 & 33.29 & 29.49 \\
\hline
\end{tabular}


0.051 for effect of spring SST, interaction with location non-significant at $p=0.80$ ). Examination of model parameter estimates (Table 4) shows that productivities were especially high on Bogoslof and especially low on Buldir, Duck, and (to a lesser extent) the Pribilofs. Warmer temperatures appeared to increase productivity on Bogoslof and the Pribilofs, while decreasing it on Buldir and Duck, although the SEs associated with these estimates were high, and thus inferences about environmental effects are uncertain.

Table 2. Rissa tridactyla. (a) Correlations and (b) significance after correcting for autocorrelation (n values in parentheses) between annual mean CORT on pairs of colonies. na: too few years in common to estimate correlation after accounting for autocorrelation; bold: statistically significant correlations

\begin{tabular}{|c|c|c|c|c|c|}
\hline & Buldir & St. George & St. Paul & Duck & Gull \\
\hline \multicolumn{6}{|c|}{ (a) Correlation } \\
\hline Bogoslof & na & -0.557 & -0.499 & 0.113 & na \\
\hline Buldir & 1.000 & na & na & na & na \\
\hline St. George & & 1.000 & 0.954 & na & na \\
\hline St. Paul & & & 1.000 & 0.127 & na \\
\hline Duck & & & & 1.000 & 0.943 \\
\hline Gull & & & & & 1.000 \\
\hline \multicolumn{6}{|c|}{ (b) p-values } \\
\hline Bogoslof & na (1) & $0.329(5)$ & $0.254(7)$ & $0.928(3)$ & na (2) \\
\hline Buldir & & na (2) & na (2) & na $(0)$ & na $(0)$ \\
\hline St. George & & & $0.029(6)$ & na (1) & na (1) \\
\hline St. Paul & & & & $0.954(7)$ & na (2) \\
\hline Duck & & & & & $0.007(6)$ \\
\hline
\end{tabular}

Table 3. Rissa tridactyla. (a) Correlations and (b) significance after correcting for autocorrelation (n values given in parentheses, along with sample sizes) between annual productivity on pairs of colonies. na: too few years in common to estimate correlation after accounting for autocorrelation; bold: statistically significant correlations

\begin{tabular}{|lccccc|}
\hline \multicolumn{7}{r}{ Buldir } & St. George & St. Paul & Duck & Gull \\
\hline (a) Correlation & & & & \\
Bogoslof & 0.469 & 0.324 & 0.414 & na & na \\
Buldir & 1.000 & 0.439 & 0.328 & -0.213 & 0.438 \\
St. George & 1.000 & $\mathbf{0 . 8 9 6}$ & -0.375 & 0.498 \\
St. Paul & & 1.000 & -0.364 & 0.564 \\
Duck & & & 1.000 & -0.810 \\
Gull & & & & 1.000 \\
(b) p-values & & & & \\
Bogoslof 0.178 (11) $0.379(11)$ & $0.275(10)$ & na (3) & na (3) \\
Buldir & $0.093(22)$ & $0.216(21)$ & $0.686(6)$ & $0.385(6)$ \\
St. George & & $\mathbf{0 . 0 0 1}(\mathbf{2 5})$ & $0.464(6)$ & $0.315(6)$ \\
St. Paul & & & $0.479(6)$ & $0.244(6)$ \\
Duck & & & & $0.131(6)$ \\
& & & & & \\
\end{tabular}
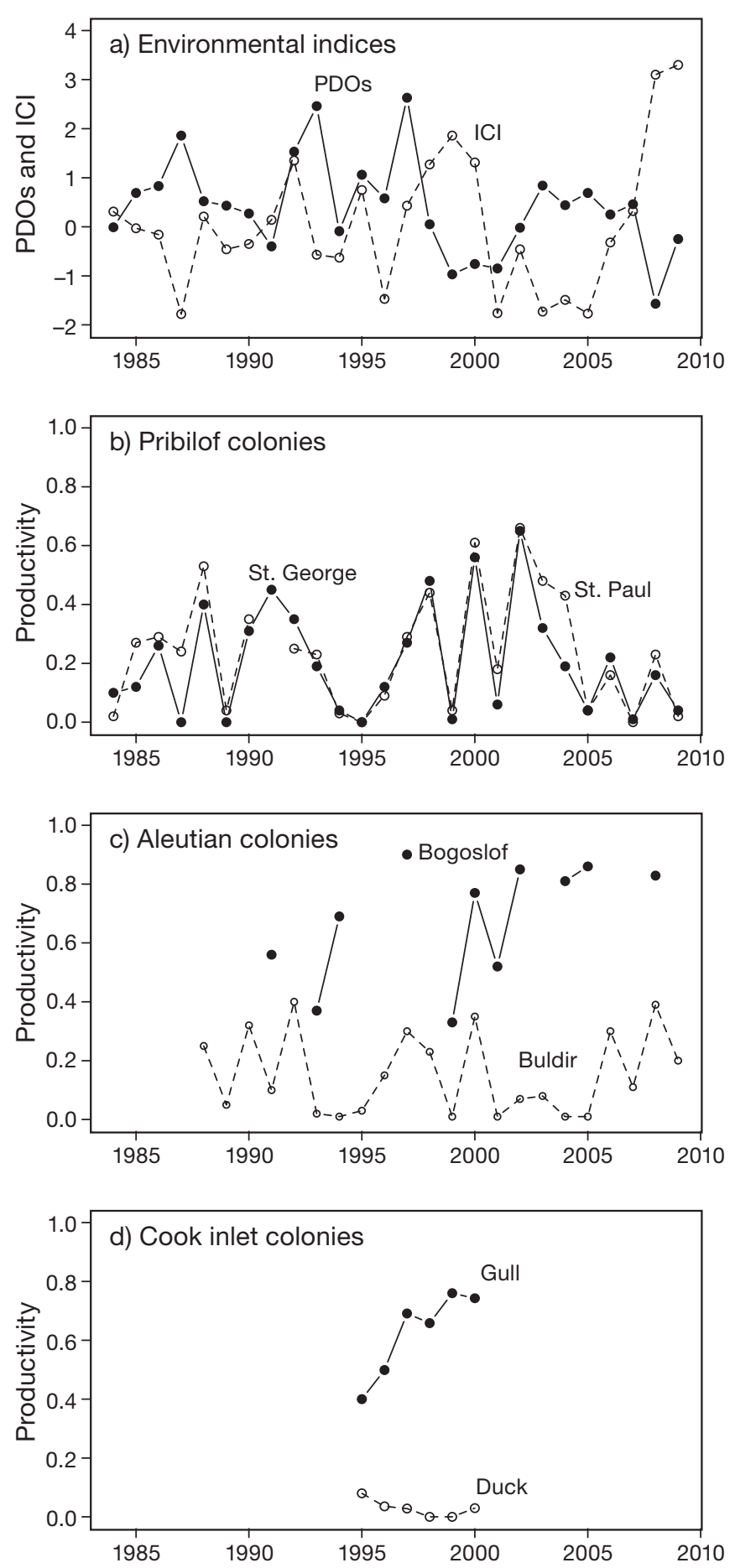

Fig. 2. Rissa tridactyla. Environmental conditions (a) as measured by PDO values (Pacific Decadal Oscillation; summer sea-surface temperature, more positive is warmer; solid line) and ICI (ice cover index; extent of winter ice cover, more positive means more ice; dashed line) matched up with productivity for (b) Pribilof colonies (•, St. George; O, St. Paul), (c) Aleutian colonies ( $\bullet$, Bogoslof; O, Buldir), and (d) Cook Inlet colonies ( $\bullet$, Gull; $\bigcirc$, Duck). For simplicity, sea-surface temperature is not shown as separate trajectories would be required for each location and season 
Table 4. Rissa tridactyla. Parameter estimates for the GLS model of productivity as a function of location, spring sea-surface temperature (SST), and their interaction. Reported intercept values are the predicted means \pm SE (logit scale) of productivity at the mean value of SST spring, while the reported slope values are the slope of the relationship between logit productivity and $z$-score-transformed SST spring. The last column gives colony means (at mean SST spring) back-transformed to the linear scale for intercept parameters or the back-transformed range predicted when the environmental index is $1 \mathrm{SD}$ below or above its long-term mean for slope parameters

\begin{tabular}{|lcc|}
\hline & $\begin{array}{c}\text { Mean } \pm \text { SE } \\
\text { (logit) }\end{array}$ & $\begin{array}{c}\text { Mean or range } \\
\text { (linear) }\end{array}$ \\
\hline Bogoslof at mean SST spring & $0.933 \pm 0.395$ & 0.708 \\
Buldir at mean SST spring & $-2.140 \pm 0.534$ & 0.095 \\
Duck at mean SST spring & $-2.871 \pm 1.540$ & 0.044 \\
Gull at mean SST spring & $0.542 \pm 1.540$ & 0.622 \\
Pribilofs at mean SST spring & $-0.730 \pm 0.756$ & 0.315 \\
Bogoslof response to SST spring & $0.549 \pm 1.289$ & $0.585-0.805$ \\
Buldir response to SST spring & $-0.365 \pm 1.855$ & $0.135-0.065$ \\
Duck response to SST spring & $-0.612 \pm 1.849$ & $0.085-0.020$ \\
Gull response to SST spring & $0.052 \pm 1.849$ & $0.610-0.634$ \\
Pribilofs response to SST spring & $0.858 \pm 1.407$ & $0.160-0.522$ \\
\hline
\end{tabular}

\section{Relationship between stress and productivity}

Productivity appeared to decrease with increasing log CORT (linear regression $\mathrm{R}^{2}=0.10, \mathrm{p}=0.04$; Fig. 4); however, CORT also varied by colony, making it unclear whether location or CORT was driving variation in productivity. Logit productivity varied significantly among locations ( $p=0.025$ in GLS, treating Pribilof colonies as a single region), but the effects of $\log$ CORT $(p=0.18)$ and its interaction with location $(\mathrm{p}=0.80)$ were not significant.

\section{Counts and population trends}

Byrd et al. (2008a) analyzed population trends on the Pribilofs from 1975 to 2005, finding evidence for stable populations

\section{Stress}

For the best-supported location set of Cook Inlet, Pribilofs, Buldir, and Bogoslof, GLS models of CORT as a function of location, environmental index, and their interactions revealed significant difference among locations and significant locationdependent effects for PDOs (location: $\mathrm{p}<0.0001$; PDOs: $\mathrm{p}=0.0001$; interaction: $p=0.0005)$ and a locationdependent effect of ICI (ICI: $p=0.65$; interaction: $p=0.013$ ), but revealed no significant effect of spring SST (spring SST: $\mathrm{p}=0.18$; interaction: $\mathrm{p}=$ $0.19)$ and only a marginally significant effect of summer SST (summer SST: $\mathrm{p}=0.28$; interaction: $\mathrm{p}=0.09$ ). Stress was highest in Buldir and the Cook Inlet colonies. In general, warmer conditions decreased stress in the Pribilofs and increased stress in Bogoslof and Cook Inlet (Table 5, Fig. 3). The more frequent occurrence of statistically significant relationships for CORT as opposed to productivity arose despite larger sample sizes for productivity.
Table 5. Rissa tridactyla. Parameter estimates for the GLS model of corticosterone (CORT) as a function of location, (a) Pacific Decadal Oscillations (PDOs) or (b) ice cover index (ICI), and their interactions. Reported intercept values are the predicted means (logit scale) of productivity at the mean value of environmental state, while the reported slope values are the slope of the relationship between logit productivity and $z$-score-transformed environmental condition. The second-to-last column gives colony means (at mean environmental condition) of CORT back-transformed to the linear scale for intercept parameters or the backtransformed range predicted when the environmental index is $1 \mathrm{SD}$ below or above its long-term mean for slope parameters. The last column gives estimated mortality probabilities corresponding to those CORT values. Note: Buldir had data from only $2 \mathrm{yr}$, both of which were warmer than average, so we do not present its estimated parameters

\begin{tabular}{|lccc|}
\hline & $\begin{array}{c}\text { Mean } \pm \text { SE } \\
(\text { log })\end{array}$ & $\begin{array}{c}\text { Mean or range } \\
\text { (linear) }\end{array}$ & $\begin{array}{c}\text { Corresponding } \\
\text { mortality }\end{array}$ \\
\hline (a) PDOs & & & \\
Bogoslof at mean PDOs & $1.562 \pm 0.122$ & 4.77 & 0.12 \\
Cook at mean PDOs & $2.146 \pm 0.135$ & 8.55 & 0.15 \\
Pribilofs at mean PDOs & $1.558 \pm 0.140$ & 4.75 & 0.12 \\
Bogoslof response to PDOs & $0.254 \pm 0.353$ & $3.70-6.14$ & $0.11-0.13$ \\
Cook response to PDOs & $0.227 \pm 0.136$ & $6.82-10.73$ & $0.14-0.18$ \\
Pribilofs response to PDOs & $-0.204 \pm 0.149$ & $5.82-3.87$ & $0.13-0.11$ \\
& & & \\
(b) ICI & & & 0.11 \\
Bogoslof at mean ICI & $1.406 \pm 0.196$ & 4.08 & 0.15 \\
Cook at mean ICI & $2.154 \pm 0.237$ & 8.62 & 0.12 \\
Pribilofs at mean ICI & $1.637 \pm 0.237$ & 5.14 & $0.11-0.11$ \\
Bogoslof response to ICI & $-0.075 \pm 0.085$ & $4.40-3.79$ & 0.14 \\
Cook response to ICI & $-0.153 \pm 0.119$ & $10.05-7.40$ & 0.13 \\
Pribilofs response to ICI & $0.124 \pm 0.102$ & $4.54-5.82$ & $0.12-0.13$ \\
\hline
\end{tabular}


CORT vs. PDOs
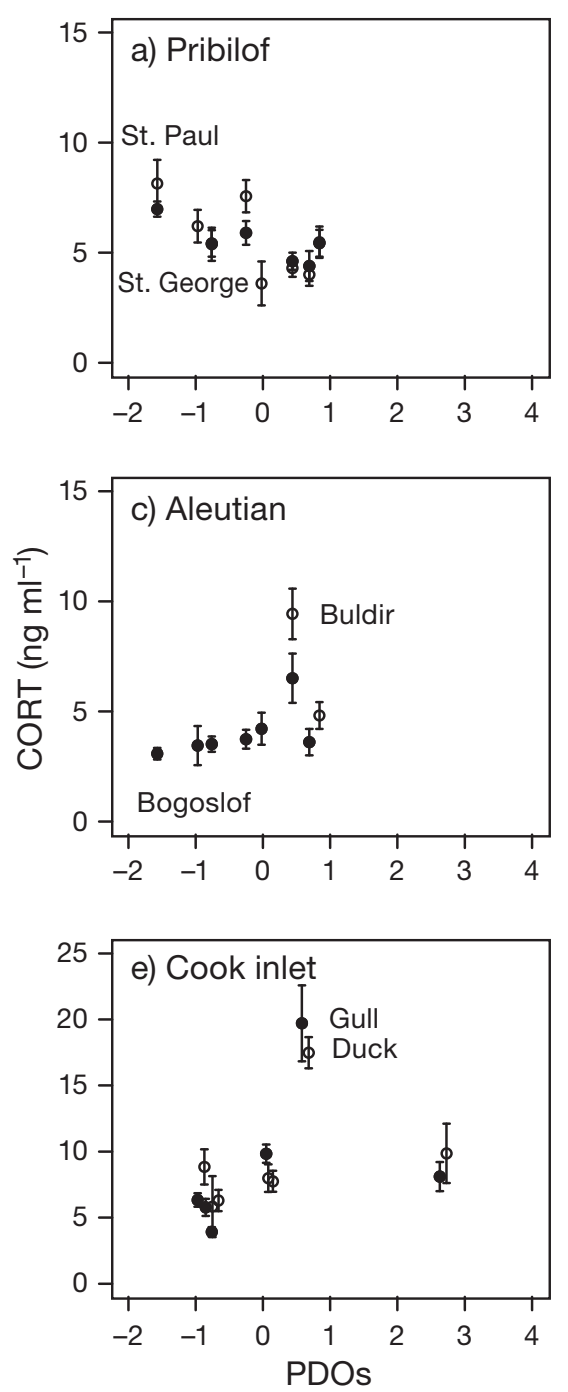

CORT vs. ICI
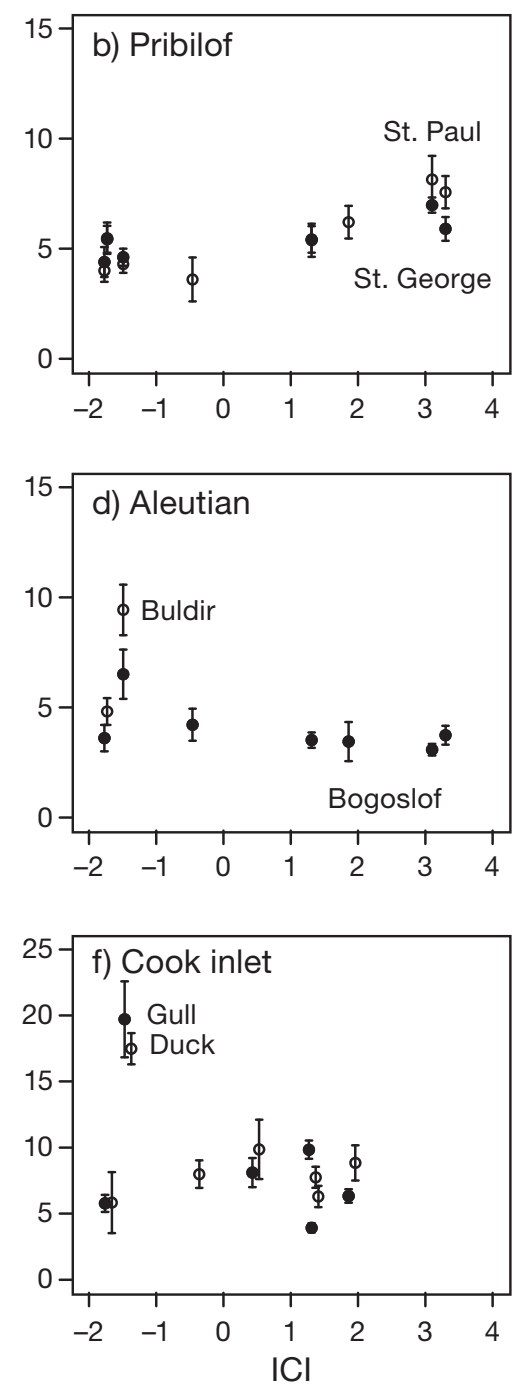

Fig. 3. Rissa tridactyla. The relationship between environmental conditions as measured by $(\mathrm{a}, \mathrm{c}, \mathrm{e})$ PDO values (Pacific Decadal Oscillation; summer sea-surface temperature, more positive is warmer) and (b,d,f) ICI (ice cover index; extent of winter ice cover, more positive means more ice) matched up with mean baseline values of corticosterone $($ CORT) for $(a, b)$ Pribilof colonies $(\bullet$, St. George; O, St. Paul), (c,d) Aleutian colonies (•, Bogoslof; O, Buldir), and (e,f) Cook Inlet colonies ( $\bullet$, Gull; $\bigcirc$, Duck). Note that for (e) and (f) the $y$-axis scale is different, and Duck Island environmental index values are dithered slightly to the right to avoid overlap. Error bars represent \pm 1 SE. For simplicity, seasurface temperature is not shown since separate trajectories would be required for each location and season

on St. George and a decrease followed by a slow increase on St. Paul. Both colonies had slightly higher numbers in 2008 compared to 2005 (Fig. S1 in Supplement 1 at www.int-res.com/articles/suppl/ m454p221_supp.pdf). Although only 3 counts are available for Bogoslof, numbers appear to have more than doubled between 2000 and 2005. No recent counts were available for Duck or Gull Island, but

black-legged kittiwakes have declined from the mid-1970s through 2000 on Duck Island, while populations on Gull Island were stable through the 1990s, following an earlier increase (Piatt 2004, his Fig. 14.9; see also Fig. S1 in Supplement 1). Counts on Buldir show a significant downward trend (log abundance decreasing by $0.027 \mathrm{yr}^{-1}$, linear regression of logged counts, $\mathrm{R}^{2}=$ $0.63, \mathrm{p}=0.001$ ).

\section{Population projections}

Table 6 summarizes the estimated mean annual adult mortality, the corresponding expected number of reproductive bouts, mean productivity, and resultant calculation of $R_{0}$, along with $95 \%$ credible intervals for each colony. Note that these are colony-specific means, with means taken over all years for which data were available; thus, they do not always match the predicted value at mean environmental state for the full time series over which environmental data are available (cf. Tables 4 \& 5). Estimated survival values were similar (within $1 \%$ ), as were most productivity values, but the productivity predicted at mean SST is higher than the observed mean for the Pribilofs ( 0.315 versus 0.206 or 0.237 ) despite nearly complete data (Fig. 2b) due to non-linearity introduced by the logit transformation. We therefore calculated $R_{0}$ based on observed means. Credible intervals on $R_{0}$ are entirely $>1.0$, corresponding to growing populations, for Bogoslof and Gull Islands. Credible intervals on $R_{0}$ are entirely $<1.0$, predicting declining populations, for Buldir, St. George, and Duck Island.

Fig. 5 illustrates the contributions of varying mortality and varying productivity to the observed range of variation in $R_{0}$. Changes in mortality from 11 to $17 \%$ are not trivial, corresponding to the minimum required productivity for a stable population increasing from 0.39 to 0.60 as mortality increases. However, even the upper range of observed mean mortalities can be compensated for with productivity well within the observed range of varia- 


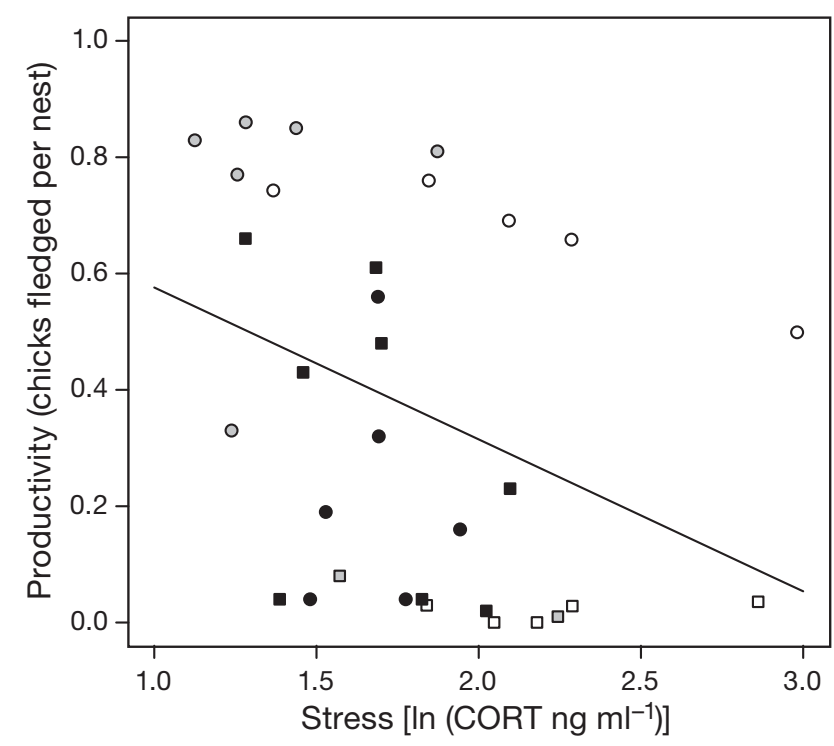

Fig. 4. Rissa tridactyla. Relationship between stress (natural $\log$ of corticosterone [CORT], ng $\mathrm{ml}^{-1}$ ) and productivity (chicks fledged nest ${ }^{-1}$ ). Black symbols $=$ Pribilof colonies $(\bullet$ St. George; $\mathbf{\bullet}$, St. Paul); grey symbols = Aleutian colonies (O, Bogoslof; $\square$, Buldir); and open symbols = Cook Inlet (Gulf of Alaska) colonies ( 0 , Gull; $\square$, Duck). The best fit linear regression (pooling colonies) is indicated by a continuous line

tion, and indeed the 2 colonies with the highest calculated $R_{0}$ include both the highest (Gull Island) and lowest (Bogoslof) predicted mortality. In contrast, the worst performing colonies are characterized by low productivities, with means at or below 0.2. As Fig. 5 illustrates, a productivity of 0.2 could only be sustained by an annual mortality $<6 \%$, while a productivity of 0.1 could only be sustained by annual mortality $<3 \%$.

Table 6. Rissa tridactyla. Demographic parameters and projected performance of each colony. Vital rates are annual means calculated for each colony. Calculations of $R_{0}$ assume a 1:1 sex ratio and survival from fledging to first reproduction of 0.57 (see 'Materials and methods-Demographic model'); $95 \%$ credible intervals (CI) on $R_{0}$ were calculated as described in Supplement 2 at www.int-res.com/articles/suppl/m454p221_supp.pdf

\begin{tabular}{|lccccc|}
\hline Colony & $\begin{array}{c}\text { Mortality } \\
(\%)\end{array}$ & $\begin{array}{c}\text { Reproductive } \\
\text { events }\end{array}$ & Productivity & $R_{0}$ & $95 \% \mathrm{CI}$ \\
\hline Bogoslof & 11.3 & 8.98 & 0.681 & 1.74 & $1.01-3.50$ \\
Buldir & 13.9 & 7.22 & 0.155 & 0.32 & $0.18-0.65$ \\
St. George & 12.3 & 8.11 & 0.206 & 0.48 & $0.24-0.97$ \\
St. Paul & 12.4 & 8.03 & 0.237 & 0.54 & $0.28-1.08$ \\
Duck & 15.9 & 6.28 & 0.029 & 0.05 & $0.02-0.36$ \\
Gull & 15.7 & 6.37 & 0.625 & 1.13 & $1.03-5.30$ \\
\hline
\end{tabular}

\section{DISCUSSION}

Adequately characterizing links between environmental conditions and the performance of organisms is a challenging task. Thus, it is perhaps not surprising that even though productivity of Rissa tridactyla was highly variable, we found weak relations between productivity and large-scale climate indices or local SSTs. Multiple factors may have competing effects that vary in strength across years, the response to any given factor may not be linear (Piatt et al. 2007, Wolf \& Mangel 2008), and responses may be in different directions in different locations. Local SST did not provide a better predictor of stress than did regional environmental indices, and only provided marginally better predictors of productivity. This may reflect the large foraging range of kittiwakes, the importance of regional processes in driving local food availability, and/or complex associations of multiple fine-scale variables that, if not directly identifiable, can be better captured by regional indices (Hallett et al. 2004). More localized measures of SST may provide increased predictive power (Shultz et al. 2009).

Nevertheless, patterns emerged from our analysis. (1) Overall relationships between environmental conditions and nutritional stress (as reflected in CORT) were stronger than relationships between environmental conditions and productivity. This is evidenced by both more significant relationships identified in GLS models and through correlations between adjacent islands in CORT being higher than correlations in productivity (Table 2 vs. Table 3 ). This suggests that large-scale climate variability is associated with variation in the physiological stress levels kittiwakes incur during reproduction. The southern colonies (western Aleutians and Cook Inlet) incurred less physiological stress during cold years (low PDO and high ICI), while the opposite was observed for the Pribilofs. Because CORT secretion is a reliable proxy for food in seabirds (Kitaysky et al. 2010), this suggests climate change may affect their food resources in opposite ways in different regions of the North Pacific.

(2) We see that climate variability (and future climate change) does not affect all locations equally, based on the lack of strong relationships between climate indices and productivity or stress for the GOA colonies and differential responses between Aleutian and Pribilof colonies 


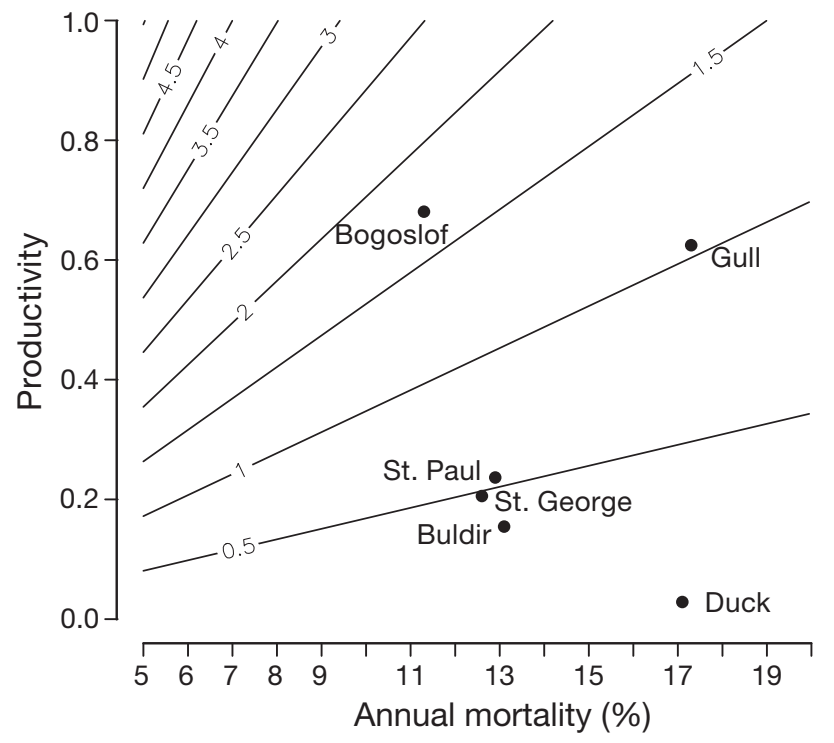

Fig. 5. Rissa tridactyla. $R_{0}$ predicted for various combinations of annual adult mortality (\%) and productivity (chicks fledged per year). $\bullet=$ annual mean mortality and productivity of each colony; contours = predicted population growth

within the Bering Sea. Similar location-specific relationships between climate and seabird performance have been observed in other systems (Gaston et al. 2005, Frederiksen et al. 2007). The differential response of different regions to climate change complicates the interpretation of which colonies are doing well and which are doing poorly. For example, overall Bogoslof hosts a higher performing colony than the Pribilofs, but in some years the Pribilof colonies may do better. In 2004 both Pribilof colonies had a lower mean CORT than Bogoslof, counter to the usual pattern.

(3) In addition, we often found correlations between performance metrics on adjacent islands (stress in the Pribilofs and Cook Inlet colonies were highly correlated between adjacent islands but not across regions, as were productivities in the Pribilofs). Correlations were lower among the Aleutian colonies, but they are much more widely separated $(\sim 1000 \mathrm{~km})$ than those among the colonies at the Pribilofs $(60 \mathrm{~km})$ or Duck and Gull Islands $(100 \mathrm{~km})$. This suggests that large-scale climate variability affects food resources on a regional basis, but does not explain variation in productivity of kittiwakes. Colony-specific drivers are not clear: potential drivers include factors as diverse as predation pressure, the quality or age of breeding individuals and their ability or willingness to buffer chicks from food shortages, and small-scale variations in prey community composition.

\section{Effects of warming}

A correlative study such as ours is unable to pinpoint explicit mechanisms, but it does identify the heterogeneity of the kittiwake responses to environmental variability in the North Pacific regions, and makes testable predictions on how different colonies may respond to warming. Warm years for the Bering Sea (increased PDOs, decreased ICI) are associated with decreased CORT in the Pribilofs. Decreased CORT corresponds to less food stress (Kitaysky et al. 2010) and an increased probability of adult survival (Satterthwaite et al. 2010). For example, estimated mortality rates (ranging between 11 and $17 \%$ ) on the Pribilofs were lowest during warm (high PDO and low ICI) compared to those during cold (low PDO and high ICI) years. Therefore, we suggest that, at least short term, warming could benefit kittiwakes in the Pribilofs as long as it does not negatively affect productivity. Of course, long-term warming may lead to complicated feedbacks throughout the food web and potentially to radically different results (Hunt et al. 2002). In addition, strengths and even signs of correlations between demography and putative environmental drivers may change over time and in different climatic regimes (Springer 1998). Indeed, Byrd et al. (2008b) reported a positive relationship between ice cover and productivity of Pribilof kittiwakes, suggesting warming could have a negative effect on productivity. We estimate a negative relationship between winter ice cover and productivity on the Pribilofs. This might partially reflect the use of different metrics for winter ice conditions, but our dataset included more recent years (especially 2008 and 2009) of both high ice cover and low productivity, whereas we excluded data before 1984, which included years of late ice retreat and high productivity.

\section{Demographic projections}

Our analyses suggest likely declines for Buldir and Duck Island and potential declines of both Pribilof colonies if current environmental conditions persist (noting, as per Fig. 2, that conditions in the North Pacific have been cold lately) and immigrants do not compensate for low survival and productivity. Given the potential biases in our survival estimates, it is not clear whether immigration is necessary to explain nearstability of the colonies (Fig. S1 in Supplement 1). Our predictions of the worst performance for Buldir and Duck and the best performance for Bogoslof and Gull are borne out by recent population trends (Fig. S1). 
Our calculations of $R_{0}$ rely on the assumption that the CORT-mortality relationship derived for kittiwakes in Cook Inlet (Satterthwaite et al. 2010) applies to other colonies and that the survival to first reproduction measured by Suryan et al. (2000) in the GOA applies to other parts of Alaska. It may be that the CORT-survival relationship varies among colonies; however, Satterthwaite et al. (2010) found little support for an interaction between CORT and colony in predicting survival, suggesting a similar form to the relationship across islands. We have no data on how survival from fledging to first reproduction varies among colonies, but, if anything, we suspect it should be lower for colonies where chick survival is lower, suggesting young are in worse condition before departing the colony. Quantitative estimates of $R_{0}$ should thus be interpreted with caution, but our conclusions about how survival tracks environmental variation are likely more robust, and the large differences in $R_{0}$ between colonies from different regions are likely good measures of their relative health and are corroborated by other evidence (e.g. increase in the Bogoslof and declines in the Buldir and Duck colonies). Thus, a demographic modeling approach based on measures of CORT and productivity may not suffice to make precise predictions of population growth rate, but does appear able to successfully predict relative performance. This is a realistic and valuable goal for applied demographic models (Beissinger \& Westphal 1998, Brook et al. 2000).

\section{Life-history considerations}

None of our population projections incorporate the effects of skipping reproduction entirely in times of poor environmental conditions. While skipped reproduction would a priori be expected to reduce population growth rates, it may not if skipping is adaptive behavior (Cam et al. 1998). Then we would expect birds to skip only when skipping carries a survival benefit (relative to breeding) such that lifetime reproductive output is expected to increase as a result. Indeed, Lanctot et al. (2003) found that kittiwakes with high CORT failed to lay eggs, and Goutte et al. (2010) found that female kittiwakes with higher CORT were more likely to skip, suggesting the most stressed birds are the most likely to skip reproduction and by doing so reducing their realized stress and mortality risk. Thus, overall survival may be higher than that estimated just for the subset of birds persisting in breeding despite harsh conditions (and sampled for CORT in our study), representing better long-term prospects for apparently declining colonies. Potential adaptive skipping might also explain the mismatch between demographic projections and recent stability in numbers in the Pribilof colonies.

Despite the importance of survival to the demography of long-lived birds, it appears to be higher productivity that is fueling the higher growth rate of the Bogoslof versus Pribilof colonies and Gull versus Duck. Our estimates of survival based on CORT varied from 68 to $89 \%$, although most values were at the high end of this range, with estimated survival always $>80 \%$, except for the Cook Inlet colonies in 1996. Other studies of Pacific black-legged kittiwakes have typically reported lower mortality (10 to $17 \%$ on Gull Island and 1 to $7 \%$ on Chisik [Duck] [Piatt 2004]; 6 to $9 \%$ on Middleton Island [Hatch et al. 1993]; $10.2 \%$ with chicks or $4.7 \%$ without in Shoup Bay [Golet et al. 1998]), so we may be underestimating adult survival. However, adult survival would have to be quite high to compensate for the low productivity on Buldir and the Pribilofs, and even higher for the near-zero productivities observed at Duck Island. At just 0.11 female chicks fledged per reproductive attempt (long-term mean for the Pribilofs), even if birds experienced $81 \%$ survival from fledging to first reproduction (much higher than the $57 \%$ estimated by Suryan et al. [2000] and corresponding to $95 \%$ annual survival for $4 \mathrm{yr}$ as a juvenile), over 11 reproductive attempts would be required for an expected $R_{0}$ of 1.0. This corresponds to an adult survival of $91 \%$ annually. Using Suryan et al.'s (2000) estimate of $57 \%$ survival from fledging to first reproduction, stability would require almost 16 reproductive events or almost $94 \%$ annual survival. For Duck Island, Piatt (2004) reported near 99\% survival from 1997 to 1998 ; however, with $95 \%$ confidence intervals for that year extending down to almost $70 \%$ that estimate seems unreliable. Estimated survival for the remaining years was near $93 \%$, corresponding to an $R_{0}$ of 0.12 given 14.3 reproductive events, 0.57 survival from chick to fledging, and mean reproductive output of 0.0145 female chicks per bout.

\section{Conclusions}

Our results reinforce the conclusion that predicting seabird response to climate variability and change is a difficult task that requires close attention to local as well as regional patterns. We predict that warming will have region-specific effects on stress, increasing predicted survival for the northern colonies and decreasing it for southern colonies. Based on our analy- 
sis, we expect productivity will be better predicted by local changes in conditions, with local spring SST offering moderate explanatory power, which is consistent with previous findings for Cook Inlet (Shultz et al. 2009).

We conclude that longevity alone may not be enough to buffer against environmental variability and, in particular, that differences between islands in productivity may have important demographic consequences even for long-lived birds. Our results suggest that self-sustaining populations in lowproductivity colonies are unlikely, even given optimistic estimates of survival. Thus, we suggest that managers do not accept low productivity on these islands as the status quo and that they do focus on identifying drivers of variation in productivity and measures to increase productivity. The apparent mismatch between a calculated $R_{0}$ below selfreplacement and near-stability or even slight increases in the recent past for St. Paul and the past $30 \mathrm{yr}$ for St. George suggest that migration or skipping of reproduction may be important additional factors in determining colony dynamics; thus, collecting data and building models to describe these processes should be a high priority. Similarly, the concordant predictions of a high $R_{0}$ and recent growth of the Bogoslof colony suggest that skipping and migration may be less of a factor there. Our current study identified testable hypotheses awaiting future investigations, while suggesting a tool for combining data on productivity and stress as a proxy for full demographic studies in the face of limited resources and climate change.

Acknowledgements. This work was supported by funding from the Exxon Valdez Oil Spill (EVOS) Trustees Council and the North Pacific Research Board (Project No. 320, Bering Sea Ecosystem Study-Bering Sea Integrated Ecosystem Research Project [BEST-BSIERP] Projects B74, B67, and B77). Financial and logistical support was also provided by Experimental Program to Stimulate Competitive Research (NSF EPSCoR), United States Geological Survey (USGS), Alaska National Wildlife Refuge, the crew of MV 'Tiglax', and the Institute of Arctic Biology University of Alaska Fairbanks. We are grateful to Evgenia Kitaiskaia for expertly conducting hormonal assays. Thank you to M. Arumitsu, C. Barger, J. Benson, D. Black, M. Benowitz-Fredericks, A. Chapman, J. Citta, T. Dempsey, I. Dorresteijn, H. Douglas, J. Figurski, M. Gray, A. Harding, G. Hoffman, C. Hovnanian, B. Keitt, R. Kitaysky, M. Litzow, K. Mangel, A. Nielsen, L. Ochikubo, R. Papish, J. Piatt, M. Post, M. Schultz, J. Sears, M. Shultz, G. Snegden, B. Smith, T. Van Pelt, M. Wada, S. Wang, J. Wetzel, S. Wright, R. Young, S. Youngren, S. Zador, and S. Zuniga for their great field work. We thank M. Benowitz-Fredericks, A. Shelton, J. Santora, J. Welcker, B. Wells, R. Young, and anonymous reviewers for helpful comments. Field work was conducted under the University of
Washington and the University of Alaska Institutional Animal Care and Use Committee (IACUC) protocols and all required federal and state permits. This paper is BESTBSIERP Publication No. 30 and North Pacific Research Board (NPRB) Publication No. 319.

\section{LITERATURE CITED}

Anderson PJ, Piatt JF (1999) Community reorganization in the Gulf of Alaska following ocean climate regime shift. Mar Ecol Prog Ser 189:117-123

Barbraud C, Rivalan P, Inchausti P, Nevoux M, Rolland V, Weimerskirch H (2011) Contrasted demographic responses facing future climate change in Southern Ocean seabirds. J Anim Ecol 80:89-100

Beissinger S, Westphal MI (1998) On the use of demographic models of population viability in endangered species management. J Wildl Manage 62:821-841

Blas J, Bortolotti GR, Tella JL, Baos R, Marchant TA (2007) Stress response during development predicts fitness in a wild, long lived vertebrate. Proc Natl Acad Sci USA 104:8880-8884

Bókony V, Lendvai AZ, Liker A, Angelier F, Wingfield JC, Chastel O (2009) Stress response and the value of reproduction: Are birds prudent parents? Am Nat 173:589-598

Brook BW, O'Grady JJ, Chapman AP, Burgman MA, Akçakaya HR, Frankham R (2000) Predictive accuracy of population viability analysis in conservation biology. Nature 404:385-387

Brown MB, Brown CR (2009) Blood sampling reduces annual survival in cliff swallows (Petrochelidon pyrrhonota). Auk 126:853-861

Brown CR, Brown MB, Raouf SA, Smith LC, Wingfield JC (2005) Effects of endogenous steroid hormone levels on annual survival in cliff swallows. Ecology 86:1034-1046

Brown CJ, Schoeman DS, Sydeman WJ, Brander K and others (2011) Quantitative approaches in climate change ecology. Glob Change Biol 17:3697-3713

Burnham KP, Anderson DR (2002) Model selection and multimodel inference: a practical-theoretic approach, 2nd edn. Springer-Verlag, Heidelberg

$>$ Byrd GV, Schmutz JA, Renner HM (2008a) Contrasting population trends of piscivorous seabirds in the Pribilof Islands: a 30-year perspective. Deep-Sea Res II 55: 1846-1855

Byrd GV, Sydeman WJ, Renner HM, Minobe S (2008b) Responses of piscivorous seabirds at the Pribilof Islands to ocean climate. Deep-Sea Res II 55:1856-1867

Cam E, Hines JE, Monnat JY, Nichols JD, Danchin E (1998) Are adult nonbreeders prudent parents? The kittiwake model. Ecology 79:2917-2930

> Coulson JC (2002) Why do adult kittiwakes survive so long but breed so poorly in the Pacific? J Avian Biol 33: 111-112

> Frederiksen M, Edwards M, Mavor RA, Wanless S (2007) Regional and annual variation in black-legged kittiwake breeding productivity is related to sea surface temperature. Mar Ecol Prog Ser 350:137-143

Freeman SL, McClintock ME, Morrison KW, Drummond BA (2010) Biological monitoring at Buldir Island, Alaska in 2009. AMNWR 2010/05, US Fish and Wildlife Service Report, Homer, AK

Gaston AJ, Gilchrist HG, Hipfner JM (2005) Climate change, ice conditions and reproduction in an Arctic nesting 
marine bird: Brunnich's guillemot (Uria lomvia L.). J Anim Ecol 74:832-841

Gelman A, Carlin JB, Stern HS, Rubin DR (2003) Bayesian data analysis, 2nd edn. Texts in statistical science. Chapman \& Hall/CRC, New York, NY

Golet GH, Irons DB, Estes JA (1998) Survival costs of chick rearing in black-legged kittiwakes. J Anim Ecol $67: 827-841$

Goutte A, Antoine E, Weimerskirch H, Chastel O (2010) Age and the timing of breeding in a long-lived bird: A role for stress hormones? Funct Ecol 24:1007-1016

- Hallett TB, Coulson T, Pilkington JG, Clutton-Brock TH, Pemberton JM, Grenfell BT (2004) Why large-scale climate indices seem to predict ecological processes better than local weather. Nature 430:71-75

Hare SR, Mantua NJ (2000) Empirical evidence for North Pacific regime shifts in 1977 and 1989. Prog Oceanogr 47:103-145

Hatch SA, Roberts BD, Fadley BS (1993) Adult survival of black-legged kittiwakes Rissa tridactyla in a Pacific colony. Ibis 135:247-254

Hunt GL Jr, Byrd GV (1999) Marine bird populations and carrying capacity of the eastern Bering Sea. In: Loughlin TR, Otani K (eds) Dynamics of the Bering Sea. University of Alaska Seagrant, Fairbanks, AK, p 631-650

Hunt GL Jr, Stabeno PJ, Walters G, Sinclair E, Brodeur RD, Napp JM, Bond NA (2002) Climate change and control of the southeastern Bering Sea pelagic ecosystem. DeepSea Res II 49:5821-5853

Hunt GL Jr, Stabeno PJ, Strom S, Napp JM (2008) Patterns of spatial and temporal variation in the marine ecosystem of the southeastern Bering Sea, with special reference to the Pribilof Domain. Deep-Sea Res II 55:1919-1944

Hunt GL Jr, Coyle KO, Eisner LB, Farley EV and others (2011) Climate impacts on eastern Bering Sea foodwebs: a synthesis of new data and an assessment of the Oscillating Control Hypothesis. ICES J Mar Sci 68: 1230-1243

Irons DB, Anker-Nilssen T, Gaston AJ, Byrd GV and others (2008) Magnitude of climate shift determines direction of circumpolar seabird population trends. Glob Change Biol 14:1455-1463

Jenouvrier S, Barbraud JC, Weimerskirch H (2005) Longterm contrasted responses to climate of two Antarctic seabird species. Ecology 86:2889-2903

> Kitaysky AS, Piatt JF, Wingfield JC (2007) Stress hormones link food availability and population processes in seabirds. Mar Ecol Prog Ser 352:245-258

Kitaysky AS, Piatt JF, Hatch SA, Kitaiskaia EV, BenowitzFredericks ZM, Shultz MT, Wingfield JC (2010) Food availability and population processes: severity of nutritional stress during reproduction predicts survival of long-lived seabirds. Funct Ecol 24:625-637

Knape J, de Valpine P (2011) Effects of weather and climate on the dynamics of animal population time series. Proc Biol Sci 278:985-992

Kotzerka J, Garthe S, Hatch SA (2010) GPS tracking devices reveal foraging strategies of black-legged kittiwakes. J Ornithol 151:459-467

> Lanctot RB, Hatch SA, Gill VA, Eens M (2003) Are corticosterone levels a good indicator of food availability and reproductive performance in a kittiwake colony? Horm Behav 43:489-502

Mantua NJ, Hare SR, Zhang Y, Wallace JM, Francis RC (1997) A Pacific interdecadal climate oscillation with impacts on salmon production. Bull Am Meteorol Soc 78:1069-1079

Martin AD, Quinn KM, Park JH (2011) MCMCpack: Markov Chain Monte Carlo in R. J Stat Softw 42:1-21

McClintock ME, Thomson G, Drummond BA (2010) Biological monitoring at St. Paul Island, Alaska in 2009 with additional observations at Otter and Walrus Islands. AMNWR 2010/06, US Fish and Wildlife Service Report, Homer, AK

Morris WF, Doak DF (2002) Quantitative conservation biology: theory and practice of population viability analysis. Sinauer Associates, Sunderland, MA

Morris WF, Pfister CA, Tuljapurkar S, Haridas CV and others (2008) Longevity can buffer plant and animal populations against changing climatic variability. Ecology 89:19-25

Mueter FJ, Litzow MA (2008) Sea ice retreat alters the biogeography of the Bering Sea continental shelf. Ecol Appl 18:309-320

> Oro D, Torres R, Rodriguez C, Drummond H (2010) Climatic influence on demographic parameters of a tropical seabird varies with age and sex. Ecology 91:1205-1214

$>$ Overland JE, Stabeno P (2004) Is the climate of the Bering Sea warming and affecting the ecosystem? Eos Trans AGU 85:309-316

Pfister CA (1998) Patterns of variance in stage-structured populations: evolutionary predictions and ecological implications. Proc Natl Acad Sci USA 95:213-218

Piatt JF, Abookire AA, Drew GS, Harding AM and others (eds) (2002) Response of seabirds to fluctuations in forage fish density. Final Report to Exxon Valdez Oil Spill Trustee Council (Restoration Project 00163M) and Minerals Management Service (Alaska OCS Region). Alaska Science Center, US Geological Survey, Anchorage, AK

Piatt JF (2004) Survival of adult murres and kittiwakes in relation to forage fish abundance. Final report to Exxon Valdez Oil Spill Restoration Project (Restoration Project 00338). US Geological Survey, Anchorage, AK

Piatt JF, Harding AMA, Shultz M, Speckman SG, van Pelt TI, Drew GS, Kettle AB (2007) Seabirds as indicators of marine food supplies: Cairns revisited. Mar Ecol Prog Ser 352:221-234

Pinheiro JC, Bates DM (2000) Mixed-effects models in S and S-PLUS. Springer, Heidelberg

Pinheiro J, Bates D, DebRoy S, Sarkar D, R Development Core Team (2010) nlme: linear and nonlinear mixed effects models. R package Version 3.1-97, http://cran. r-project.org/web/packages/nlme/index.html (accessed March 19, 2012)

Pyper RJ, Peterman RM (1998) Comparison of methods to account for autocorrelation in correlation analyses of fish data. Can J Fish Aquat Sci 55:2127-2140

R Development Core Team (2009) R: a language and environment for statistical computing. $\mathrm{R}$ Foundation for Statistical Computing, Vienna, Austria. Available at: http: //www.R-project.org.

Renner HM, Williams JC (2005) Marine bird surveys at Bogoslof Island, Alaska, in 2005. AMNWR 05/18, US Fish and Wildlife Service Report, Homer, AK

> Romero LM, Wikelski M (2001) Corticosterone levels predict survival probabilities of Galapagos marine iguanas during El Nino events. Proc Natl Acad Sci USA 98: 7366-7370

Sandvik H, Erikstad K (2008) Seabird life histories and climatic fluctuations: a phylogenetic-comparative time 
series analysis of North Atlantic seabirds. Ecography 31:73-83

Satterthwaite WH, Kitaysky AS, Hatch SA, Piatt JF, Mangel $M$ (2010) Unifying quantitative life history theory and field endocrinology to assess prudent parenthood in a long-lived seabird. Evol Ecol Res 12:779-792

Shannon P, Drummond BA, Thomsen SK (2010) Biological monitoring at St. George Island, Alaska in 2010. AMNWR 2010/07, US Fish and Wildlife Service Report, Homer, AK

Sheldon LD, Chin EH, Gill ASA, Schmaltz G, Newman AEM, Soma KK (2008) Effects of blood collection on wild birds: an update. J Avian Biol 39:369-378

Shultz MT, Kitaysky AS (2008) Spatial and temporal dynamics of corticosterone and corticosterone binding globulin are driven by environmental heterogeneity. Gen Comp Endocrinol 155:717-728

Shultz MT, Piatt JF, Harding AM, Kettle AB, Van Pelt TI (2009) Timing of breeding and reproductive performance in murres and kittiwakes reflect mismatched seasonal prey dynamics. Mar Ecol Prog Ser 393:247-258

Smith TM, Reynolds RW, Peterson TC, Lawrimore J (2008) Improvements to NOAA's historical merged land-ocean surface temperature analysis (1880-2006). J Clim 21: 2283-2296

Springer AM (1998) Is it all climate change? Why marine bird and mammal populations fluctuate in the North

Submitted: April 4, 2011; Accepted: December 5, 2011
Pacific. In: Holloway G, Muller P, Henderson D (eds) Proceedings of the 10th 'Aha Huliko' a Hawaiian winter workshop on biotic impacts of extratropical climate variability in the Pacific, January 26-30, 1998. SOEST Special Publication, Honolulu, HI, p 121-125

Suryan RM, Irons DB, Benson J, Kaufman M (2000) Foraging ecology, reproductive biology, and population dynamics of black-legged kittiwakes (Rissa tridactyla) in Prince William Sound, Alaska. In: Duffy DC (ed) APEX project: Alaska predator ecosystem experiment in Prince William Sound and the Gulf of Alaska, Exxon Valdez oil spill restoration project final report (restoration project 00163, Appendix E). Exxon Valdez Trustee Council, Anchorage, AK

Warton DI, Hui FKC (2011) The arcsine is asinine: the analysis of proportions in ecology. Ecology 92:3-10

Wisdom MJ, Mills LS, Doak DF (2000) Life-stage simulation analysis: estimating vital rate effects on population growth for conservation. Ecology 81:628-641

> Wolf N, Mangel M (2008) Multiple hypothesis testing and the declining-population paradigm in Steller sea lions. Ecol Appl 18:1932-1955

> Wolf SG, Sydeman WJ, Hipfner JM, Abraham CL, Tershy BR, Croll DA (2009) Range-wide reproductive consequences of ocean climate variability for the seabird Cassin's auklet. Ecology 90:742-753

Proofs received from author(s): March 21, 2012 